\section{Correlation between Bond Strength to Dentin and Sealers Penetration by Push-Out Test and CLSM Analysis}

Maybell Tedesco ${ }^{1} @$, Marcelo Carvalho Chain ${ }^{1} @$, Wilson Tadeu Felippe ${ }^{1}{ }^{\circ}$, Ana Maria Hecke Alves ${ }^{1}{ }^{\circ}$, Lucas da Fonseca Roberti Garcia ${ }^{1} \odot$, Eduardo Antunes

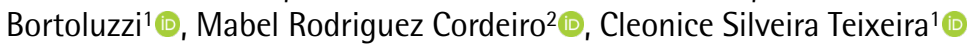

'Department of Dentistry, Endodontics Division, Health Sciences Center, UFSC - Universidade Federal de Santa Catarina, Florianópolis, SC, Brazil ${ }^{2}$ Department of Morphological Sciences, UFSC - Universidade Federal de Santa Catarina, Florianópolis, SC, Brazil

Correspondence: Cleonice Silveira Teixeira, Departamento de Odontologia, Centro de Ciências da Saúde, UFSC, Rua Delfino Conti, s/n, 88040-370 Florianópolis, SC, Brasil. Tel: +55-48-3721-5840. e-mail: cleonice.teixeira@ufsc.br

Key Words: endodontics, root canal obturation, root canal filling materials, confocal.

\section{Introduction}

The conclusion of the endodontic treatment requires a tridimensional filling of the root canal system with a non-irritating material (1). Gutta-percha cones are the first choice as filling material due to their suitable physical, chemical and biological properties (2). In addition, this material is flexible and can be used with different techniques (2). However, gutta-percha cones do not bond to the root canal walls and, therefore, a sealer is necessary to attach them to the dentin and fill the empty spaces (2).

Despite the different compositions of the root canal sealers, all of them are used for the same purpose, root canal filling (3). However, such differences may affect the physical and mechanical properties and, consequently, the interaction of the sealers with dentin (3). Zinc oxide-based sealers are the most used for root canal filling, regardless their low resistance to compressive forces and the poor ability to penetrate the dentinal tubules (4). Conversely, epoxy resin-based sealers have higher capacity to penetrate into dentinal tubules (4) and higher adhesion to radicular dentin (5). On the other hand, the interaction of mineral aggregate-based sealers with dentin results in a process called biomineralization (6).
For this reason, it is important to evaluate and to compare the ability of endodontic sealers to penetrate into dentinal tubules, and the adhesion characteristics of these sealers to radicular dentin $(4,6)$. Several studies have reported that the filling material properly adapted to root dentin can reduce the infiltration of fluids and microorganisms $(1,5)$. In addition, the higher adhesion to dentin increases the bond strength of the filling material to dislodgement, which is desirable especially to teeth that receive intraradicular retainers (7).

The sealer penetration and the adhesive interface formed between filling material and dentin can be evaluated by different methods $(3,4)$. The Confocal laser scanning microscopy (CLSM) is a tool that allows a proper analysis, due to the possibility to visualize clearly, and with few artefacts, the sealer tags present into the dentinal tubules (8).

There are many studies related to the analysis of the adhesive interface $(3,4,8)$. However, few studies have made the correlation between the bond strength to dentin, the quality of the interface and depth of penetration of root canal sealers $(9,10)$. Therefore, the purpose of this study was to verify the existence of a correlation between bond 
strength to dentin and depth of penetration of three root canal sealers of different bases: Endofill, AH Plus and MTA Fillapex, by push-out test and analysis of the adhesive interface using CLSM. The null hypothesis tested was that there is no correlation between bond strength and intratubular penetration, regardless the sealer tested.

\section{Material and Methods}

\section{Tooth Selection and Root Canal Preparation}

This study was previously approved by the Ethics Committee of Federal University of Santa Catarina for using human teeth. Eighty freshly extracted human mandibular premolars were initially stored in $0.1 \%$ thymol solution $(\mathrm{pH} 7,0)$ at $4^{\circ} \mathrm{C}$, followed by washing in taper water for $36 \mathrm{~h}$ for disinfection. Next, the teeth were radiographed in both mesio-distal and bucco-lingual directions and examined in stereoscopic lens under $\times 4$ magnification (Illuminated Magnifying Glass, Tokyo, Japan) to select teeth with a single and straight root canal, free of caries or previous restorations, without curvatures or microcracks, and a fully formed apical foramen. Then, the crowns were transversely sectioned $2 \mathrm{~mm}$ from the cement enamel junction with a 0.15 diamond saw (Isomet 1000, Buehler, Lake Bluff, IL, USA) at low speed, under copious water cooling. The access cavity was made and the roots with large oval canals were replaced in order to minimize canals without round section after endodontic preparation. After all, forty-five roots were selected for the study. The roots length was standardized at $16 \mathrm{~mm}$, and the working length was established at $1 \mathrm{~mm}$ from the apical foramen. Root canal preparation was performed according to the crown-down technique by initially using sizes 4 to 2 Gates-Glidden drills (Union Broach, York, PA, USA), followed by instrumentation with ProTaper Universal system (Dentsply-Maillefer, Ballaigues, Switzerland), incrementally, up to the F5 instrument, as recommended by the manufacturer. Root canals were irrigated with 2 $\mathrm{mL}$ of $1 \%$ sodium hypochlorite solution at each change of instrument. After final irrigation with $3 \mathrm{~mL}$ of $17 \%$ EDTA and $3 \mathrm{~mL}$ of $1 \%$ sodium hypochlorite solution, the root canals were completely dried with absorbent paper points (Dentsply-Maillefer).

The roots were then randomly assigned into three groups $(n=15)$, according to the root canal sealer used for filling: Endofill (Dentsply, Petrópolis, RJ, Brazil); AH Plus (Dentsply DeTrey, Konstanz, Germany) and MTA Fillapex (Angelus, Londrina, PR, Brazil) (Table 1). In each group, five root canals were filled with sealer containing $0.1 \%$ wt Rhodamine B dye (Sigma-Aldrich, St. Louis, MO, USA), to allow CLSM analysis. Root canal filling was performed using master and accessories gutta-percha cones (Dentsply-Maillefer) by the cold lateral condensation technique. After vertical compaction and placement of provisional restoration (Citodur, Dorident, Vienna, Austria), the roots were stored in $100 \%$ relative humidity at $37^{\circ} \mathrm{C}$ for 7 days.

\section{Push-Out Test}

The specimens were sectioned perpendicular to the root long axis on a cutting machine (Isomet 1000) using a diamond saw (Isomet 1000, Buehler) at low speed and under copious water cooling. Two $1.0 \mathrm{~mm}$-thick slices were obtained from each root third (coronal, middle and apical). Thirty slices per group were tested for bond strength. The slices obtained from the other five roots, which were filled incorporating the rhodamine $B$, were kept in an environment protected from the light and moisture, until analysis under CLSM (9).

Each slice was marked on its apical side and individually attached to a metallic surface containing a $2.5 \mathrm{~mm}$ diameter hole at its center, adapted to the lower portion of the universal testing machine (Instron Model 4444, Instron, Canton, MA, USA). The push-out test was performed by applying a compressive load to the apical side of each section by using cylindrical plungers (with tip diameter of 0.6 to $1.0 \mathrm{~mm}$, selected according to the root canal diameter of the slice tested), attached to the upper portion of the Instron machine, with a crosshead speed of $0.5 \mathrm{~mm} / \mathrm{min}(4,5)$. To express the bond strength in mega pascals (MPa), the load at failure recorded in Newton (N) was divided by the lateral area (SL) in $\mathrm{mm}^{2}$ of

Table 1. Root canal sealers used in the experimental procedures, with their respective manufacturer, composition and batch number

\begin{tabular}{ccc}
\hline Sealer (Manufacturer) & Composition & Batch number \\
\hline Endofill (Denstply, & Zinc oxide; hydrogenated resin, bismuth subcarbonate, barium & $365439 \mathrm{C}$ \\
Petrópolis, RJ, Brazil) & sulfate, sodium borate, eugenol and sweet almond oil & Paste A: Bisphenol-F epoxy resin, calcium tungstate, \\
& zirconium oxide, silica, iron oxide pigments. & 0705000020 \\
AH Plus (Denstply DeTrey, & Paste B: dibenzyldiamine, aminoadamantane, tricyclodecanediamine & calcium tungstate, zirconium oxide, silica and silicone oil \\
Konstanz, Germany) & Salicylate resin, resin diluent, natural resin, bismuth \\
MTA Fillapex (Angelus, & oxide, silica nanoparticles, MTA, pigments \\
Londrina, PR, Brazil) &
\end{tabular}


the root canal filling. SL was calculated by the formula of a conical frustum: $S L=(R+r)\left[h^{2}+(R-r)^{2}\right] 1 / 2$, where: $R$ is the mean radius of the coronal canal, $r$ is the mean radius of the apical canal, and $\mathrm{h}$ is the height relative to the tapered inverted cone ( $\mathrm{mm})(4)$.

\section{Failure Mode Analysis}

For the failure mode analysis, the debonded areas were examined under stereomicroscope at $\times 20$ to $\times 40$ magnifications (Stereo Discovery V12, Carl Zeiss Microlmaging $\mathrm{GmbH}$, Göttingen, Germany). The failures were classified according to the criteria established on a previous study (4), as follows: adhesive failure (root canal sealer totally separated from dentin); cohesive failure (failure within the material, with remaining dentin covered by sealer); and mixed failure (mixture of adhesive and cohesive failure modes). Scores were attributed to the failure modes (score $1=$ adhesive failure, score $2=$ mixed failure, and score $3=$ cohesive failure).

\section{CLSM Analysis}

Fifteen slices of each one of the three groups, which were not submitted to push-out test, were assessed by CLSM. Each slice was positioned on a double-sided tape, with the face to be observed turned down. Then, the specimens were embedded in epoxy resin.

After $24 \mathrm{~h}$, the specimens were polished with silicon carbide sandpaper (Norton, São Paulo, SP, Brazil) in a decreasing order of granulation (up to 1,200), and with alumina pastes of $0.3 \mu \mathrm{m}$ and $0.1 \mu \mathrm{m}$ grits (Arotec, São Paulo, $\mathrm{SP}$, Brazil), under copious water refrigeration. Afterwards, the specimens were washed in an ultrasonic tank for 10 min and dried at $37^{\circ} \mathrm{C}$, applied in histological glass slides and mounted with glass cover slips. The samples were analyzed by CLSM (Leica DMI6000 B Microscope, Germany). The images were obtained in a mono-fluorescence mode from the surface up to $20 \mu \mathrm{m}$ in depth, under $\times 100$ and $\times 400$ magnifications. The sample was excited (excitation at $543 \mathrm{~nm}$ ) and the detector range was set to $540-620$ $\mathrm{nm}$ (pick fluorescence wavelength of $568 \mathrm{~nm}$ ). For the presence, quantity and depth of penetration of the root

Table 2. Mean values (MPa), standard deviation (SD), and error (E) for the bond strength of the sealers, regardless the root canal portion

\begin{tabular}{cccc}
\hline Sealers & Mean values & SD & E \\
\hline Endofill & $2.30 \mathrm{a}$ & 1.03 & 0.19 \\
AH Plus & $4.17 \mathrm{~b}$ & 1.86 & 0.31 \\
MTA Fillapex & 3.13a & 1.96 & 0.34 \\
\hline
\end{tabular}

*Different letters indicate significant difference among root canal sealers. The ANOVA and post hoc Tukey test, $\alpha=5 \%$. canal sealers into the dentinal tubules (tags), a score system (0-3) was used to classify the findings: 0 - absence of tags, 1 - tags $<20 \mu \mathrm{m}$ (presence of few and short tags); 2 - tags ranging from 20 to $100 \mu \mathrm{m}$ in length and in greater quantity; 3 - tags $>100 \mu \mathrm{m}$ (dense and long tags) (4). Two different and previously calibrated examiners performed the CLSM analysis in a blind manner. In case of discrepancy between the two examiners, the analysis was reviewed until agreement.

\section{Statistical Analysis}

The software SPSS 17.0 for Windows (SPSS Inc, Chicago, IL, USA) was used for statistical analysis of the data. Homogeneity and normality of sample were tested by Levene's and Kolmogorov-Smirnov's tests, respectively. The outcome data of the push-out test were analyzed statistically by two-way analysis of variance (ANOVA), comparing the variables: sealers and root canal thirds. Post hoc pair-wise multiple comparisons were performed using Tukey test. Non-parametric data resulting from CLSM analysis were submitted to Kruskal-Wallis and Mann-Whitney tests. To evaluate the correlation between the bond strength data, or the failure pattern data, and the intratubular penetration data was applied the Kendall correlation test and the Pearson correlation test, respectively. The level of statistical significance was set at $\alpha=0.05$.

\section{Results}

\section{Bond Strength}

The means values (MPa) of bond strength obtained from push-out test, for each group and root canal thirds, may be seen in Table 2 (comparison among sealers) and Figure 1 (comparison among sealers and root canal thirds). The two-way ANOVA revealed statistically significant difference of BS among Endofill, AH Plus and MTA Fillapex groups $(p<0.001)$ and root canal thirds $(p<0.001)$. In general, the

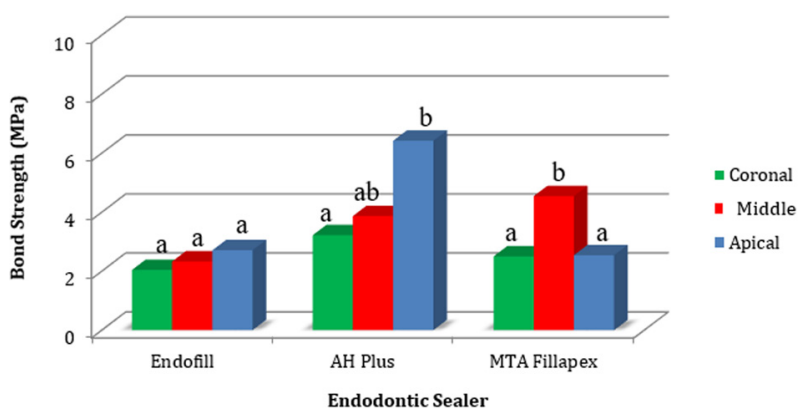

Figure 1. Graphic representation of the bond strength (MPa) comparison among sealers at the different root canal thirds (coronal, middle and apical). *Different letters over columns indicate statistical significant difference. Two way-ANOVA and post hoc Tukey tests, $\alpha=5 \%$. 
AH Plus sealer had higher bond strength values than the other sealers, especially at the coronal and apical thirds $(p<0.001)$. Endofill and MTA Fillapex groups had the lowest values of bond strength. Significant difference was observed $(p<0.05)$ among the root canal thirds (coronal, middle and apical) only for AH Plus and MTA Fillapex groups (Fig. 1).

The failure pattern distribution (\%) in each root canal third after the push-out test may be seen in Table 3. There was a predominance of cohesive failure in the specimens of the AH Plus (70\%) and MTA Fillapex (63.33\%) groups, and with less frequency in Endofill group (40\%). Adhesive failure was mostly observed in Endofill group (56.67\%), followed by MTA Fillapex (36.67\%) and AH Plus groups (30\%). Mixed failure occurred only in the Endofill group (3.33\%).

\section{Depth of Penetration Assessment}

The results from the analysis of the images obtained by CLSM for the depth of penetration of the root canal sealers into the dentinal tubules are exposed in Figure 2 and illustrated in Figure 3. The statistical analysis revealed higher quantity of dense and long tags (score $3-\geq 100$ $\vec{\sigma} \mu \mathrm{m})$ in the specimens of the AH Plus sealer $(p<0.05)$, in comparison with the Endofill and MTA Fillapex groups,
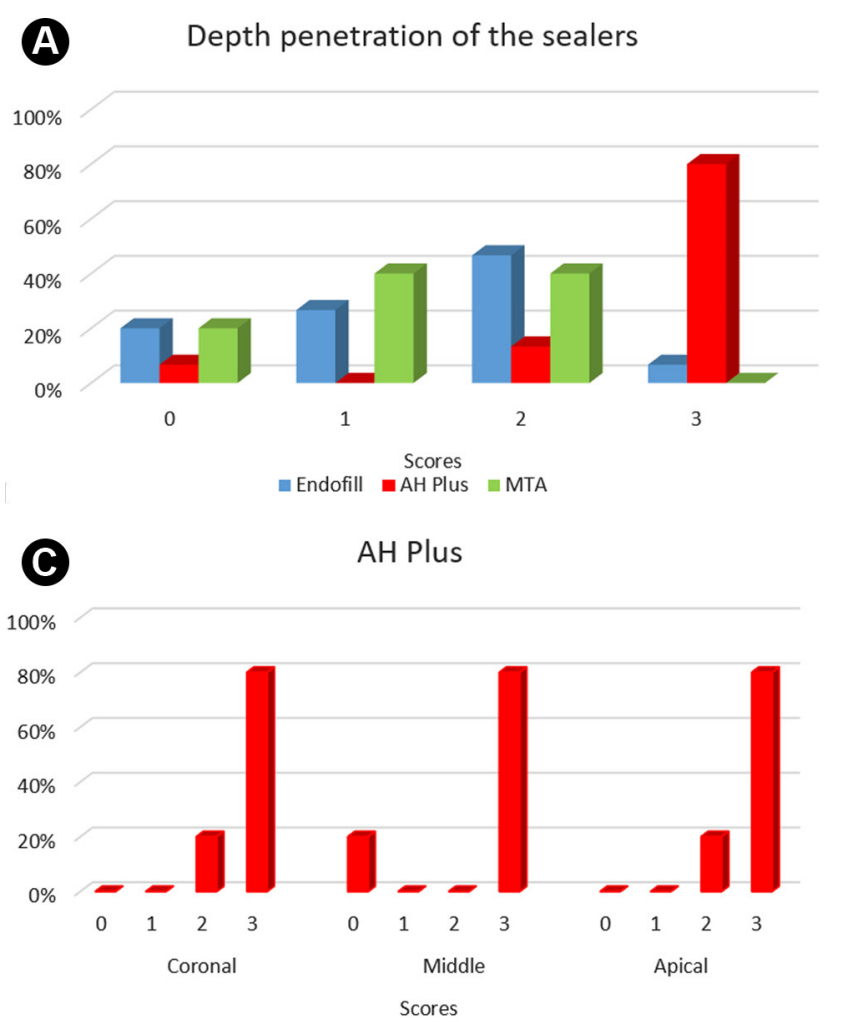

which were statistically similar ( $p>0.05)$.

The comparison among the root canal thirds (coronal, middle and apical) inside each group did not showed

Table 3. Failure pattern distribution (\%) in each root canal third after the push-out test

\begin{tabular}{lcccc}
\hline \multirow{2}{*}{ Sealer } & $\begin{array}{c}\text { Root } \\
\text { Canal } \\
\text { Third }\end{array}$ & $\begin{array}{c}\text { Adhesive } \\
\text { Failure }\end{array}$ & $\begin{array}{c}\text { Cohesive } \\
\text { Failure }\end{array}$ & $\begin{array}{c}\text { Mixed } \\
\text { Failure }\end{array}$ \\
\hline \multirow{2}{*}{ Endofill } & Coronal & $40 \%$ & $60 \%$ & $0 \%$ \\
& Middle & $60 \%$ & $40 \%$ & $0 \%$ \\
& Apical & $70 \%$ & $20 \%$ & $10 \%$ \\
AH Plus & Coronal & $10 \%$ & $90 \%$ & $0 \%$ \\
& Middle & $10 \%$ & $90 \%$ & $0 \%$ \\
& Apical & $70 \%$ & $30 \%$ & $0 \%$ \\
Millapex & & & & \\
& Coronal & $0 \%$ & $100 \%$ & $0 \%$ \\
& Middle & $30 \%$ & $70 \%$ & $0 \%$ \\
\hline & Apical & $80 \%$ & $20 \%$ & $0 \%$ \\
\hline
\end{tabular}
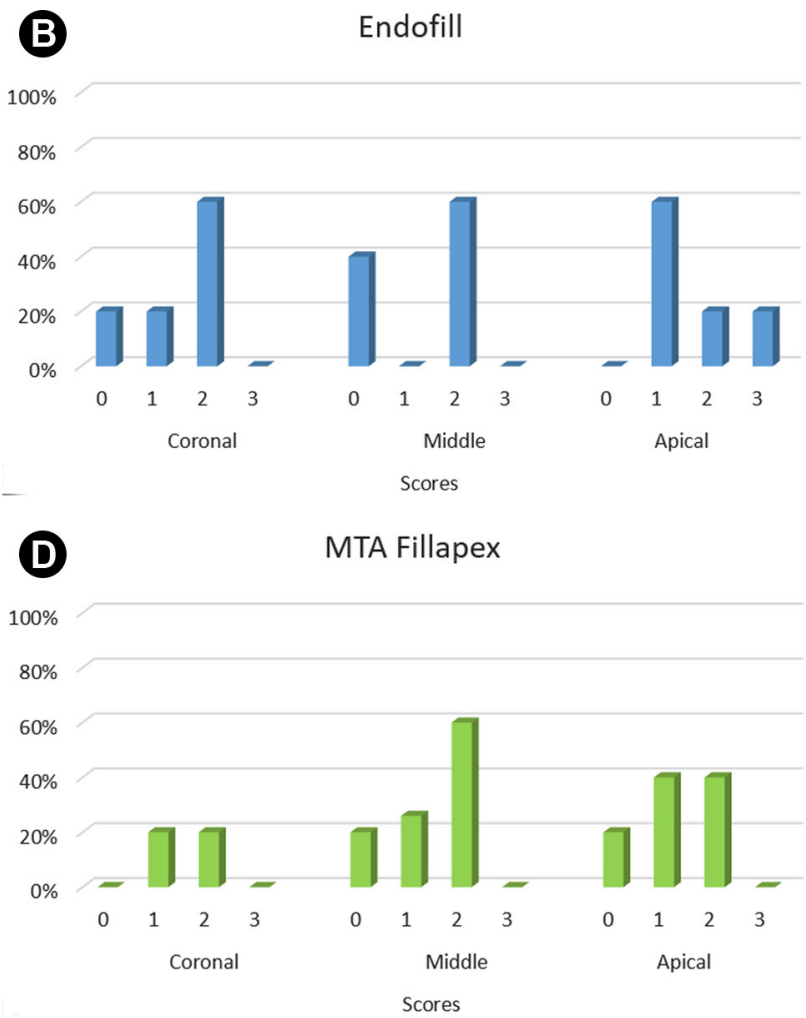

Figure 2. Depth of penetration of the different root canal sealers (Endofill, AH Plus and MTA Fillapex). A: Scores (\%) obtained for every sealer, regardless of the root canal third evaluated. B, C and D: Scores (\%) obtained for every sealer at the different root canal thirds evaluated (coronal, middle and apical). 

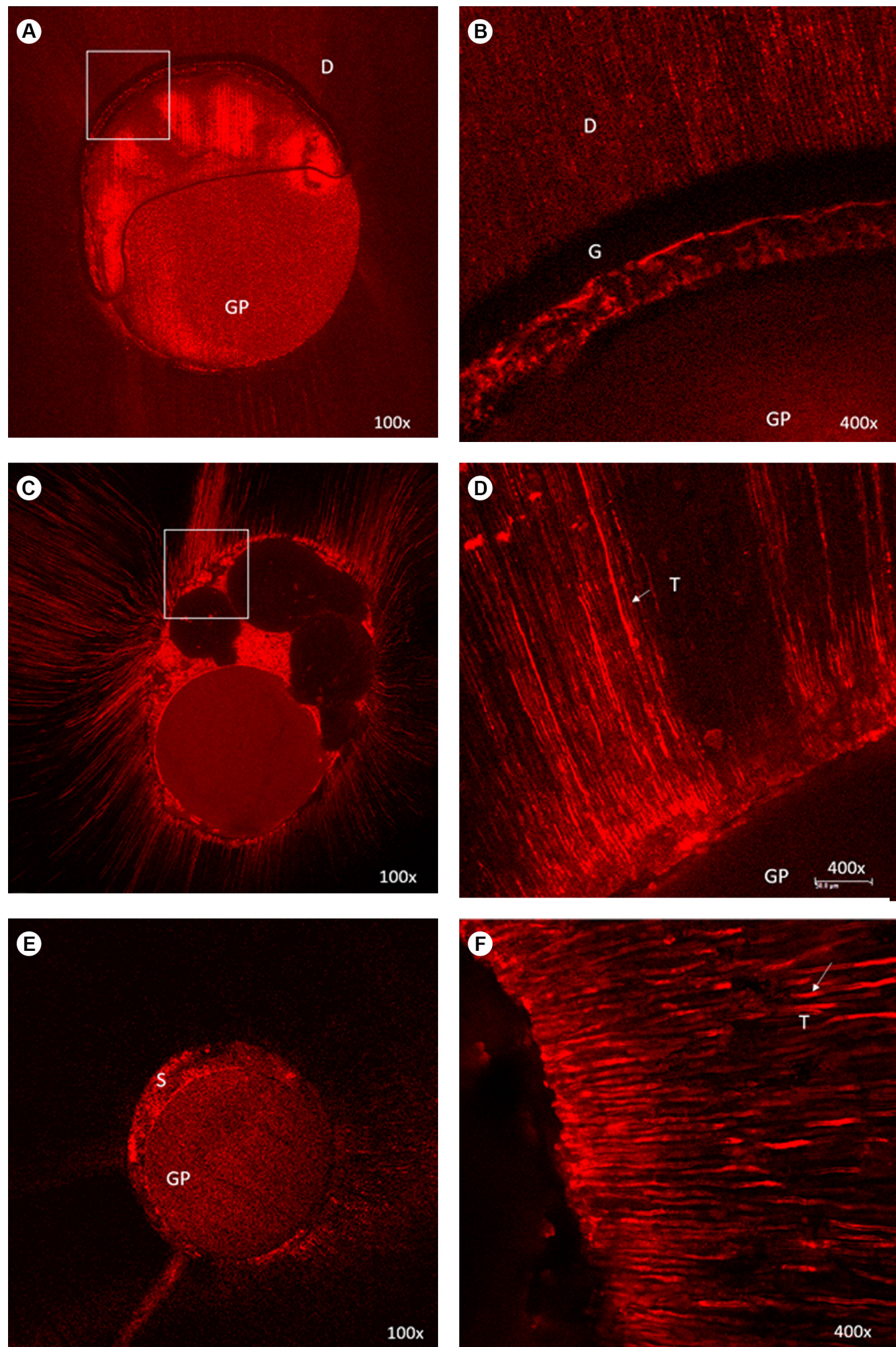

Figure 3. Representative CLSM images of the adaptation and depth of penetration of the root canal sealers: Endofill (A) and (B), AH Plus (C) and (D); and MTA Fillapex (E) and (F). A: Middle third of a root canal filled with Endofill (100x). B: Higher magnification (400x). Note the presence of gaps (G) between the gutta-percha and the dentin (D). A small quantity of sealer tags within the dentinal tubules can be seen. C: Representative image of the interface formed between AH Plus and dentin (100x). D: Higher magnification (400x) of the area showing the presence of longer tags; and in higher quantity. E: Representative images of a root canal filled with MTA Fillapex (100x). F: Higher magnification (400x). It is possible to observe long tags (arrow). S: sealer; GP: guta-percha; G: gaps, D: dentin; T: Sealer. 
statistical difference $(p>0.05)$ in the penetration depth of sealers into the dentinal tubules (Fig. 3 ).

\section{Correlation Analysis}

The results of the correlation analysis are exposed in the Tables 4 and 5. The Kendall test (Table 4), correlation between BS to dentin and depth of penetration into dentinal tubules) and the Pearson test (Table 5), correlation between failures pattern and depth of penetration into dentinal tubules) did not show correlation between the variables evaluated for all the tested sealers $(p>0.05)$.

\section{Discussion}

This study assessed the correlation between BS to dentin and depth of penetration of root canal sealers into dentinal tubules by push-out test and analysis of the adhesive interface by CLSM. In addition, the correlation between failure pattern after the push-out test and depth of dentinal penetration of the sealers was also verified. According to the results obtained, the null hypothesis tested was accepted, as no correlation between bond strength, or between failure pattern, and intratubular penetration were confirmed by the Kendall test and by the Pearson test $\vec{s}$ respectively. This result corroborates with other studies that have shown that sealers adhesiveness to the dentin walls cannot be attributed merely to penetration depth of the sealers into dentinal tubules $(10,11)$. It is well known that the adhesion in the root canal dentin is a complex process (7). Because it depends not only on the physical and chemical interaction between the molecules present in the sealers and dentinal walls, but also the adhesion is directly related to frictional resistance of the filling material on the surrounding walls of the root canal $(4,7)$.

The anatomic features of the teeth used in the present study were standardized by a proper radiographic examination performed in both mesio-distal and buccolingual directions. Furthermore, after the root canal access, a careful stereoscopic ( $\times 4$ magnification) inspection was performed to unsure the choice of teeth with similar root canal conditions, replacing the ones with large oval canals and flattened roots.

Root canal sealers of different bases were used in this study, with diverse compositions and, consequently, diverse

Table 4. Coefficient of correlation (Kendall test) and p-value of the correlation between bond strength and depth of penetration

\begin{tabular}{lcc}
\hline Sealers & Correlation Coefficient & $\mathrm{p}$ value \\
\hline Endofill & -0.146 & 0.488 \\
AH Plus & -0.144 & 0.518 \\
MTA Fillapex & 0.046 & 0.830 \\
\hline
\end{tabular}

physical and chemical properties (12). Higher values of bond strength to dentin were obtained when the AH Plus sealer was used, which showed statistically significant difference in comparison with the other root canal sealers. These results are endorsed by other studies, which confirm the excellence of this sealer $(13,14)$. The AH Plus is composed by epoxy resin and amines (14). The epoxy resin reacts with the collagen of the dentin, forming a covalent bond with it, which increases the bond strength of this sealer to root dentin (14). Interestingly, the BS to dentin of this sealer was significantly higher in the apical third of the root canal. This result can be explained, in part, by the higher frictional resistance of the filling material against root canal walls in that region (4), both due to anatomy and high pressure applied on the surface by the lateral compaction technique used during root canal filling.

The BS values obtained for the zinc oxide-based sealer (Endofill) and the mineral aggregate-based sealer (MTA Fillapex) in the present study were similar, as reported by other study (4). Despite of its low adhesion to dentin, zinc oxide-based sealers are widely used in several clinical procedures (15). This type of sealer has low resistance to compression, and low cohesion of its molecules, which can explain the low BS to dentin, and the highest number of adhesive failures verified after the push-out test (4).

Although some authors presume that cohesive failures are related with higher BS to dentin, in the case of zinc oxide-based sealers, the low cohesion of its molecules can promote the fracture of the material, even when the sealer is submitted to lower compressive forces $(4,16)$.

Similarly, lower bond strength values of MTA Fillapex sealer have been reported in previous studies $(3,16)$. The addition of other chemical components to develop MTA-based sealers, besides the original mineral trioxide aggregate (MTA), aimed to enhance the flow ability, and to allow its use as a root canal filling material (4). Nevertheless, these changes compromised other physical-chemical properties, as the setting time, dimensional changes and bond strength to dentin (17). To complete the setting reaction, the MTA Fillapex needs the presence of salicylate resin in a ratio of 1:1 in its composition (18). Studies have

Table 5. Coefficient of correlation (Pearson test) and p-value of the correlation between failure pattern and depth of penetration

\begin{tabular}{lcc}
\hline Sealers & Correlation Coefficient & $p$ value \\
\hline Endofill & -0.459 & 0.086 \\
AH Plus & -0.327 & 0.234 \\
MTA Fillapex & -0.134 & 0.635 \\
\hline
\end{tabular}


reported that the high salicylate proportion in this sealer may be responsible for its properties of extended setting time and working time, excessive flow ability, disturbance in calcium-silicate properties and solubility $(18,19)$. The increase dimensional changes of MTA Fillapex, caused by its solubility and great flow ability, may interfere in the sealer penetration into dentinal tubules, accessory canals and anatomical irregularities, causing a sealer detachment from dentinal walls (20). Still, an initial volumetric shrinkage during setting period is verified in the root canal sealers containing salicylate and other resinous components, which enhances the contraction factor $(18,19)$.

Considering the different root canal thirds, the bond strength values obtained in the present study corroborate with the study of Sagsen et al. (21). Higher bond strength values were observed at the middle and apical thirds, and this result possibly may be related with the forces applied during the lateral compaction when root canal filling was performed $(21,22)$. Such force increases the frictional strength of the sealer against the root canal walls, and consequently, contributes to the adhesion of the sealer to dentin substrate $(4,22)$.

The failure modes analysis showed most frequently cohesive failures in AH Plus and MTA Fillapex groups. The presence of cohesive failure in AH Plus group can be explained by the higher bond strength of the sealer to dentin, and the deeper sealer penetration into the dentinal tubules (14). Conversely, the adhesive failure in most of the specimens from the Endofill group might be explained by the low bond strength of zinc- oxide based sealers to root dentin $(4,9,16)$.

In the present study, in all sealers analyzed, a weak or negligible correlation was found between the failures pattern and penetration of the sealers into dentinal tubules. This result was easily seen in the AH Plus sealer, which had great intratubular penetration in all canal thirds, independently of the failure type observed.

The use of the CLSM in the present study allowed the observation of dense and long tags, especially in the specimens of the epoxy-resin based sealer, as reported in other studies $(9,10,21)$. This observational method is widely used to assess adhesion between materials and dentin due to the high contrast, which allows a proper analysis of the sealer into the dentinal tubules $(9,20)$. In addition, CLSM allows assessment of the dentin substrate in depth; and the $0.1 \%$ Rhodamine $B$ dye added to the sealers allowed a clear visualization of the sealer's tags in its entire length $(9,20)$.

Machado et al. (10) evaluated a possible correlation between intratubular penetration, adhesion and apical infiltration in root canals filled with gutta-percha and an epoxy resin-based sealer. Infiltration tests were performed in 60 mandibular central incisors, which later, were seccionated in slices and evaluated under stereomicroscope, considering the intratubular penetration in the middle portion of the root canal. After microscopic analysis, the sections were submitted to the push-out test. The data showed no correlation between bond strength, intratubular penetration of the sealers and apical infiltration.

Despite the lack of correlation between these variables, the penetration of sealers into dentinal tubules still is considered beneficial (22). The presence of sealer into dentinal tubules increases the mechanical interlocking (12); and creates a physical barrier that may confine remaining microorganisms, enhancing the antibacterial effect of the sealer (23).

However, it is also valid to emphasize that the specimens submitted to CLSM were not evaluated by the push-out test, since $0.1 \%$ wt Rhodamine B was added to the tested sealers. Previous studies verified that Rhodamine B has a deleterious effect on the mechanical properties of adhesive systems $(14,24)$. In addition, a preliminary study (data not yet published) verified that the addition of rhodamine $B$ negatively influenced the bond strength of MTA Fillapex. Therefore, only the specimens without Rhodamine B were tested aiming to avoid a risk of bias in the study. In addition, studies published by other authors used a similar methodology, with the push out test performed only in the specimens without Rhodamine B addition (25).

Within the limitations of an ex vivo study, it is possible to conclude that the epoxy resin-based sealer showed higher bond strength and sealer intratubular penetration than the other tested sealers. Considering the different compositions and properties of the sealers, there is no correlation between bond strength and intratubular penetration. Accordingly, it was observed no significant correlation between the intratubular penetration and the failure pattern in the sealers tested. Further studies are necessary to evaluate the influence of the incorporation of fluorescence dyes, as the rhodamine $B$, in the physical-chemical properties of the root canal sealers.

\section{Resumo}

Este estudo correlacionou a resistência de união (RU) e a penetração de cimentos de diferentes bases à dentina radicular por meio do teste push-out e da análise por microscopia Confocal a laser (MCL). Quarenta e cinco canais radiculares foram preparados pela técnica coroa-ápice e obturados com guta-percha associada aos seguintes cimentos $(n=15)$ : Endofill, AH Plus e MTA Fillapex. Para análise por MCL da penetração dos cimentos, cinco canais foram obturados com os cimentos manipulados com Rodamina B a 0,1\%. Em seguida, os espécimes foram seccionados transversalmente e submetidos ao teste de push-out $(n=10)$ e análise por MCL $(n=5)$. Os dados da RU apresentaram as seguintes médias (MPa) e desvio padrão: $\operatorname{AH}$ Plus $(4,17 \pm 1,86)$; MTA Fillapex $(3,13 \pm 1,96)$ e Endofill $(2,10 \pm 1,03)$. A análise estatística (two-way ANOVA, $\alpha=0,05)$ mostrou diferença significativa entre os cimentos $(p<0,001)$ e as regiões do canal radicular $(p<0,001)$. Os resultados de RU de Endofill e MTA Fillapex foram estatisticamente semelhantes ( $p>0,05)$, no entanto, foram estatisticamente 
diferentes de AH Plus $(p<0,001)$. A análise regional da RU demonstrou semelhança entre as regiões média e apical $(p>0,05)$, e ambas foram diferentes da região cervical $(p<0,001)$. A análise por $M C L$ verificou a formação de tags em todos os grupos, com maior penetração nos espécimes obturados com AH Plus $(p<0,05)$. 0 teste de Kendall (correlação entre RU à dentina e profundidade de penetração dos cimentos na dentina) e o teste de Pearson (correlação entre o padrão de falha e a profundidade de penetração dos cimentos na dentina) não evidenciaram correlação significativa entre as variáveis avaliadas nos cimentos testados $(p<0,05)$. 0 grupo AH Plus apresentou maior RU, e formação de tags mais profundos que os outros cimentos. Não houve correlação significativa entre RU e penetração intratubular dos cimentos testados.

\section{Acknowledgements}

The authors would like to thank the LCME team of the Federal University of Santa Catarina that allowed the SEM analysis. This study was supported in part by the Coordination of Training of Higher Education Graduates (CAPES), and the Research Support Foundation of the State of Santa Catarina (FAPESC, grant \# 10027/2012-7).

\section{References}

1. DeLong $\mathrm{C}, \mathrm{He} J$, Woodmansey KF. The effect of obturation technique on the push-out bond strength of calcium silicate sealers. J Endod 2015;41:385-388.

2. Soo WK, Thong $Y L$, Gutmann JL. A comparison of four guttapercha filling techniques in simulated C-shaped canals. Int Endod J 2015;48:736-746.

3. Balguerie $E$, van der Sluis L, Vallaeys K, Gurgel-Georgelin M, Diemer F. Sealer penetration and adaptation in the dentinal tubules: a scanning electron microscopic study. J Endod 2011;37:1576-1579.

4. Tedesco M, Felippe MC, Felippe WT, Alves AM, Bortoluzzi EA, Teixeira $\mathrm{CS}$. Adhesive interface and bond strength of endodontic sealers to root canal dentine after immersion in phosphate-buffered saline. Microsc Res Tech 2014;77:1015-1022.

5. Carvalho NK, Prado MC, Senna PM, Neves AA, Souza EM, Fidel SR, et al. Do smear-layer removal agents affect the push-out bond strength of calcium silicate-based endodontic sealers? Int Endod J 2017;50:612619.

6. Reyes-Carmona JF, Felippe MS, Felippe WT. The biomineralization ability of mineral trioxide aggregate and portland cement on dentine enhances the push-out strength. J Endod 2010;36:286-291.

7. Fisher MA, Berzins DW, Bahcall JK. An in vitro comparison of bond strength of various obturation materials to root canal dentin using a push-out test design. J Endod 2007;33:856-858.

8. Bitter K, Paris S, Pfuertner C, Neumann K, Kielbassa AM. Morphological and bond strength evaluation of different resin cements to root dentin. Eur J Oral Sci 2009;117:326-333.

9. Tedesco M, Chain MC, Bortoluzzi EA, da Fonseca Roberti Garcia L, Alves $\mathrm{AMH}$, Teixeira CS. Comparison of two observational methods, scanning electron and confocal laser scanning microscopies, in the adhesive interface analysis of endodontic sealers to root dentine. Clin Oral Investig 2018;22:2353-2361.

10. Machado R, Silva Neto UX, Carneiro E, Fariniuk LF, Westphalen VP, Cunha RS. Lack of correlation between tubular dentine cement penetration, adhesiveness and leakage in roots filled with gutta percha and an endodontic cement based on epoxy amine resin. J Appl Oral Sci
2014;22:22-28.

11. Haragushiku GA, Teixeira CS, Furuse AY, Sousa YT, De Sousa Neto MD, Silva RG. Analysis of the interface and bond strength of resin based endodontic cement to root dentine. Microsc Res Tech 2012;75:655661.

12. Mamootil $\mathrm{K}$, Messer HH. Penetration of dentinal tubules by endodontic sealer cements in extracted teeth and in vivo. Int Endod J 2007;40:873881.

13. Silva EJ, Carvalho NK, Prado MC, Zanon M, Senna PM, Souza EM, et al. Push-out bond strength of injectable pozzolan-based root canal sealer. J Endod 2016;42:1656-1659.

14. Machado R, Garcia LDFR, da Silva Neto UX, Cruz Filho AMD, Silva RG, Vansan LP. Evaluation of 17\% EDTA and 10\% citric acid in smear layer removal and tubular dentin sealer penetration. Microsc Res Tech 2018;81:275-282.

15. Pilownic KJ, Gomes APN, Wang ZJ, Almeida LHS, Romano AR, Shen Y, et al. Physicochemical and biological evaluation of endodontic filling materials for primary teeth. Braz Dent J 2017;28:578-586

16. Nagas E, Uyanik MO, Eymirli A, Cehreli ZC, Vallittu PK, Lassila LV, et al. Dentin moisture conditions affect the adhesion of root canal sealers. $J$ Endod 2012;38:240-244.

17. Oliveira DS, Cardoso ML, Queiroz TF, Silva EJ, Souza EM, De-Deus G. Suboptimal push-out bond strengths of calcium silicate-based sealers. Int Endod J 2015;49:796-801.

18. Vitti RP, Prati C, Sinhoreti MA, Zanchi CH, Souza E Silva MG, Ogliari FA, et al. Chemical-physical properties of experimental root canal sealers based on butyl ethylene glycol disalicylate and MTA. Dent Mater 2013;29:1287-9124.

19. Prado MC, Carvalho NK, Vitti RP, Ogliari FA, Sassone LM, Silva EJNL. Bond strength of experimental root canal sealers based on mta and butyl ethylene glycol disalicylate. Braz Dent J 2018;29:195-201.

20. Amoroso-Silva PA, Guimarães BM, Marciano MA, Duarte MA, Cavenago BC, Ordinola-Zapata R, Almeida MM, Moraes IG. Microscopic analysis of the quality of obturation and physical properties of MTA Fillapex. Microsc Res Tech 2014;77:1031-1036.

21. Sagsen $B$, Ustün $Y$, Demirbuga $S$, Pala K. Push-out bond strength of two new calcium silicate-based endodontic sealers to root canal dentine. Int Endod J 2011;44:1088-1091.

22. Macedo LMD, Silva-Sousa Y, Silva SRCD, Baratto SSP, Baratto-Filho F, Abi Rached-Júnior FJ. Influence of root canal filling techniques on sealer penetration and bond strength to dentin. Braz Dent $J$ 2017;28:380-384.

23. Wang $Z$, Shen $Y$, Haapasalo M. Dentin extends the antibacterial effect of endodontic sealers against Enterococcus faecalis biofilms. J Endod 2014;40:505-508.

24. Wang $L$, Bim 0 Júnior, Lopes AC, Francisconi-Dos-Rios LF, Maenosono $\mathrm{RM}, \mathrm{D}$ 'Alpino $\mathrm{PH}$, et al. Water interaction and bond strength to dentin of dye-labelled adhesive as a function of the addition of rhodamine $B$. J Appl Oral Sci 2016;24:317-324.

25. Wiesse PEB, Silva-Sousa YT, Pereira RD, Estrela C, Domingues LM, Pécora JD, Sousa-Neto MD. Effect of ultrasonic and sonic activation of root canal sealers on the push-out bond strength and interfacial adaptation to root canal dentine. Int Endod J 2018;51:102-111.

Received March 29, 2019

Accepted May 19, 2019 